\title{
$\begin{array}{ll}\text { Research Square } & \text { Preprints are preliminary reports that have not undergone peer review. } \\ \text { They should not be considered conclusive, used to inform clinical practice, }\end{array}$ or referenced by the media as validated information. \\ Identifying the research advances on COVID-19, the economy and the environment: network- bibliometric analysis and statistical validation
}

\section{Carlo Drago}

University Niccolo Cusano: Universita degli Studi Niccolo Cusano

Andrea Gatto ( $\nabla$ andrea.gatto@uniparthenope.it)

University of Greenwich Natural Resources Institute https://orcid.org/0000-0003-1005-3571

\section{Research Article}

Keywords: Coronavirus, economy, environment, research production, bibliometric analysis, social network analysis, community detection

Posted Date: December 16th, 2021

DOI: https://doi.org/10.21203/rs.3.rs-1142513/v1

License: (c) (i) This work is licensed under a Creative Commons Attribution 4.0 International License.

Read Full License 


\title{
Identifying the research advances on COVID-19, the economy and the environment: network-
} bibliometric analysis and statistical validation

\begin{abstract}
The COVID-19 outbreak highlights the need for urgent research. The current corpus of COVID-19 publications is increasingly rising. In the course of scientific production, social and environmental sciences tend to be overlooked or even ignored. Environmental Economics lags behind a variety of other fields on our scholarship. This paper addresses the current research and development level in Coronavirus disease, the economy, and the environment. To achieve these ends, a bibliometric analysis of these three interwoven areas is performed. The bibliometric analysis allows the synthesis of the current literature and shows the relevant patterns in research as the most relevant thematic "cores". These items can be used to interpret the existing literature but also to identify relevant future developments. We created a database of all the central publications within the scientific literature and listed the key terms associated with each publication. To discover the structural characteristics of the co-occurrence network, we measured the density and the centre. Four statistically significant groups are recognised as literature semantic cores, including environmental health, economic effects and lifestyle, presenting the highest possible interconnection. It is discovered a relationship between the Coronavirus and the economy and that this relationship exists in Environmental Economics. The analysis of environmental aspects and environment-economy interplay within the current Coronavirus pandemic claims a more punctual academic development, resulting not yet significant and scarcely explored and signals the need to improve public and environmental health scholarship response.
\end{abstract}

Keywords: Coronavirus; economy; environment; research production; bibliometric analysis; social network analysis; community detection.

JEL codes: C02, I15, I18, O13, Q56 
COVID-19 pandemic has highly influenced every aspect of life worldwide. Several research activities have been undertaken to better analyse and explore the causes, the treatment, but also the prevention of the new Coronavirus as the epidemic continues to develop (Acter et al. 2020). One of the main research objectives is to analyse the effects of the relationships between the COVID-19, the economy and the environment. In this context, urban dynamics are determinant. In fact, the effects of the pandemic on global cities need to be clarified and some relevant lessons need to be learned on urban planning and design for post-COVID (Sharifi and Khavarian-Garmsir, 2020). Early studies on the effects of the COVID-19 on urban growth consider primarily four main themes: the quality of the environment, the social and the economic impacts, the urban designs related to transport, and governance and management issues (Sharifi and Khavarian-Garmsir, 2020).

Also, water-related impacts are evolving as effects related to the COVID-19 pandemic. These effects include measures to recognise those impacts and prevent future impacts both on the water ecosystem and human health (Bandala et al., 2021). The impacts of COVID-19 is also the central topic pursued by Shakil et al. (2020). The authors determine some groups in the recent research corpus - namely, the deterioration of the environment and COVID-19, the pandemic and air quality, COVID-19 and climate/metrological variables, and temperature and COVID-19. The authors suggest a research agenda on COVID-19 and climate (Shakil et al., 2020). Zambrano-Monserrate et al. (2020) show a significant relationship between anti-COVID-19 policy measures and the environment. The authors note an amount of negative impactful factors, and a decrease in recycling and a waste production increase. Consequently, land, water, and air are exposed to danger by pollution and contamination. Finally, the authors note some improvements in clean beaches, air quality, and lower environmental noise.

The reviewed studies are of great relevance but show the need for an objective approach. Here comes the relevance of bibliometrics. By using bibliometric analyses, it is possible to map a 
research area, and in this way, to represent the connections between the various publications and the authors on the field. At the same time, it is possible to determine the most relevant works within the existing literature (El Mohadab et al., 2020).

\section{Current Environmental Economics research on Coronavirus}

Bibliometrics has inherently addressed the issue of mapping existing publication record and pulsing research question. The technique is of worth to examine hot bottom issues and, specifically, ecological and global health topics as the ongoing COVID-19 pandemic (Gatto and Drago 2020a, Ho and Gatto 2020, Gatto et al. 2020). Therefore, acquiring swift data and mapping on preliminary research amidst the current pandemic is a priority and motivates the importance of this study.

To date, limited research on converging social and environmental sciences topics has been conducted to investigate the 2019 Coronavirus. The topic poses delicate questions when it comes to the quality of academic information, scientific cooperation and, broadly, data availability with the scope to expedite and improve sound research (Homolak et al. 2020). Intuitively, the vast majority of papers have been published in health science and related disciplines (Ho and Gatto 2020). Yet an array of works on the economic impact of the Coronavirus on economic activity have been published (see Fernandes 2020). Adding to this, the relations between Coronavirus, sustainability and development emerges as an urgent matter to be examined (UN News 2020). This research field is receiving increasing scientific attention (Gatto et al. 2020).

The current work aims at extrapolating and depicting up-to-date literature on the Coronaviruseconomy-environment nexus. Following Liu et al. (2018) nexus approaches allow analysing to concurrently the existing interactions between different sectors. The authors highlight the issue that solving one problem can possibly lead to the exacerbation of another problem. In this context, it is necessary to explore the systems to discover different situations in which trade-offs exist between 
sectors and relevant potential synergies. Nexus approaches have the expressive potential to promote better governance and management practices. The aim is discovering relevant synergies and tradeoffs using quantitative techniques (The Lancet Digital Health, 2021; Kurian, 2017).

The study makes use of bibliometric analysis, network analysis and community detection with the objective to extract the semantic core from the literature on COVID-19, the economy and the environment. The semantic core is based on the most relevant keywords that appear strongly connected within the co-occurrence network identifiable once inspecting the existing literature. The semantic cores also show different concepts which can be potentially part of the nexus (the advantage of bibliometric analysis is their capacity to connect multiple relevant concepts in the scholarship by multiple sectors). The paper proceeds by detecting the call for explorations in Environmental Economics related to COVID-19 motivated by the lack of investigations - as compared to other disciplines. In this vein, the bulk of existing papers is detected, statistically analysed and discussed.

Following, the data and methodology used are approached. Here we present the perspective followed to examine the identified literature. Furthermore, we disentangle the underlying detection exercise run to detect the most relevant concepts in the literature. Hence, results are presented and assessed. From the exploratory analysis of the bibliometric data, we analyse the network structure and the relevant groups of keywords on these publications - i. e. the semantic cores. In that context, we consider as a hypothesis the community stability as a way to validate our findings. So we use computational inference in order to test the stability of our semantic cores. Where the null hypothesis is reached, we can determine if we are in presence of significant structured contents in our literature. Concluding remarks close the paper. The Appendix shows the different membership for the keywords considered on the work, divided by community membership. 
The emergence of Covid-19 has been globally relevant and disruptive. Rapid health, governance and practice response has emerged, along with the need for preparedness and resilience action to contrast emerging vulnerability (Gatto and Drago, 2020a). Cooperation in diverse areas has shown to be compulsory to avoid the insurgence and spread of the outbreak. So was the need for tailored and interdisciplinary research (Ho and Gatto, 2020). It arises the need to organise a response from national governments and the inter-governmental organisations - above all the $\mathrm{WHO}$ - as for health policies indications (WHO 2020). It results that environmental health is the centre of our analysis and is nowadays related to the adequate design of public health policies.

\section{Bibliometric analysis and Scopus database}

In order to analyse the literature related to COVID-19, the economy and the environment, it is made use of the following query from Scopus - chosen as a prime bibliographic databases see Falagas et al. (2008):

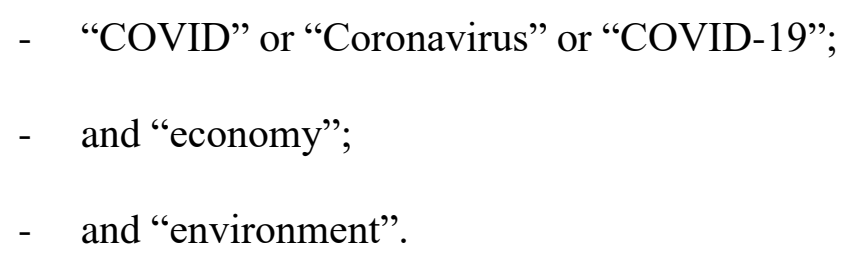

The query was lastly performed the day $11 / 6 / 2020$. From the results, we are able to construct the bibliometric dataset and perform the data analysis. The whole bibliometrics methodology used is visualised in figure 1 . The procedure is based on four phases: 
- finally, from the sorting network, we are able to decompose the network by identifying the "communities" of keywords that are maximally connected.

125 More particularly, an exploratory data analysis is performed to examine the structure of the existing 126 literature on these topics at the date. From the extraction, we obtain 15 articles that are simultaneously 127 relevant for the "COVID", or "Coronavirus" or "Covid-19", the "economy" and the "environment". 128 The outputs from the resulting bibliometric and statistical analysis (see Aria and Cuccurullo 2017) 129 show a fragmented scenario. All the sorting articles were published in 2020, and each author shows 130 a maximum of one publication in the reviewed literature.

The core of the literature analysis lies in network exploration. This analysis allows for exploring the sorting network (Wasserman Faust 1994). We consider the keywords being relevant piece of information to analyse the literature structure. We start from the adjacency matrix of the different cooccurrences of the keywords. Thus, in each article, we can observe the co-occurrence of the different considered keywords.

Co-occurrences networks are a key element in bibliometric analyses (Van Eck Waltman 2014). The analysis of the co-occurrences allows examining keywords occurring simultaneously in different articles. We consider publications that are characterised by the same keywords in the title or the abstract. Analysing the co-occurrence network allows discovering relevant statistical patterns related to a single topic. In fact, the most central keywords in the co-occurrence network constitute the most central topics in the literature. The high-central keywords on the co-occurrence network are recurrent themes within the literature and each connected keyword shows the presence of both the keywords in an article.

The final network is based on 94 vertices or nodes and 1674 edges or links. Where a co-occurrence of a keyword on the article exists, we can observe a single link between the two keywords. The first 
step is to analyse the network structure. Figure $\mathbf{2}$ shows a visualisation of the different steps of the analysis: a structural analysis of the network based on the analysis of the general features of the network (for instance the density) is first performed. Then, we identify the most central concepts of the network. Lastly, we are able to decompose the network to find the relevant groups of keywords presenting the maximal mutual interconnection.

For this scope, it is possible to analyse some structural indexes, showing their relevant characteristics (Wasserman Faust 1994, Csardi Nepusz 2006). These features are useful to introduce the analysis of the centrality of the network. This aspect is truly relevant in our work, being associable with the identification of the most relevant keywords of the literature (see also Borgatti 2005 on centrality and network flows). In fact, the feature of having a central position on the network means displaying a particular role in the literature. For this reason, it could be important to observe these keywords since these can be considered the most substantive concepts to refer to in this literature.

We took into account two relevant centrality indexes: the Freeman degree and the betweenness. Both the indexes are cardinal and are oriented to measure different centrality patterns. In the first case, we can consider a centrality index which measures the "local centrality" of a node, whereas in the second case it is displayed a centrality index which measures the "global centrality" of a node (Bader et al. 2007). From the analysis of both the centrality indexes, we are able to identify the most relevant topics in the literature.

Lastly, we took into consideration the different community structure of the network (Fortunato and Castellano 2007, Lancichinetti and Fortunato 2009, Drago Ricciuti 2017, Drago 2017, Drago Balzanella 2015) whereby we are able to identify relevant groups of different keywords which tend to be linked more intensively each other with respect to the other groups. The different "communities" shows relevant characteristics. 
Communities are groups of keywords that are highly connected to each other - so they are many times co-occurrent on the same papers - and weakly connected with the keywords which are part of other communities (Fortunato 2010).

The identified communities are groups of co-occurrent keywords that can be found in different articles. These keywords show a unique relevant "semantic core" albeit being part of different articles. Analysing the diverse keywords that are part of these communities, it is possible to retrieve and extract some related and important concepts which allow summarising the literature. This way, it is possible to conclude that communities allow interpreting the hot themes and topics in the literature thanks to their logical interconnections.

We detect the different communities assessing the "walktrap" algorithm (Pons Latapy 2005). This algorithm identifies the nodes that are part of the same group of maximally connected nodes. Short random walks in the network tend to remain on the same group of nodes or in the same community (Csardi Nepusz 2006). The walktrap algorithm identifies the nodes in which these random walks tend to stay.

The community detection approach diverges from the cluster analysis because, making use of the former, we are explicitly partitioning the network to identify the nodes which show mutually a higher level of connectivity as a group. The cluster analysis does not necessarily involve mutually interconnected nodes. That is why the membership can be interpreted as relevant groups of nodes inside the network. The identified communities are also validated considering an approach based on a test on the stability of the partitions against random perturbations of the initial network (Carissimo et al., 2018). This procedure is useful to support the significance and the robustness of our results. In order to better understand the relationships between the keywords on the communities identified, an additional exploratory analysis is performed on the "aspects of life", starting from the results of the first bibliometric analysis. 

network keywords maximally connected

\section{Additional Bibliometric Exploratory Analysis}

\section{Statistical results on preliminary research}

210 From the main outputs, we get a statistical analysis of the literature considered. More detailly, we 211 start from the characteristics of the works, in which we observe 14 different sources, for all the works 212 of the literature, 94 keywords plus (ID) and 86 author's keywords (on average 6 keywords per article). 213 For the period considered (1 January 2020-11 June 2020), it is noticeable a number of citation of 0.13 214 where the figure of the authors is on 110 on all the papers. Each author has got 0.136 articles, and the 
number of authors per document is 7.33. Only 3 authors out of 110 are single authors within the articles. It is possible to conclude from this part of the analysis that the literature is fairly scattered. The result is confirmed from the publishing journals evaluation. All the journals scrutinised have published only one article on this literature.

The higher number of published works in a journal on a topic is an important signal for the researcher: the higher number of publications and citations means a higher interest in the same topic and the capacity to attract readers. Overall, a good research strategy using bibliometric analyses may be to submit to journals in higher ranks because they are probabilistically interested in the topic and can attract more readers and citations.

The most cited papers show an extremely shattered scenario. At the same time, the most productive countries and also the most cited by publications, show a very similar situation. There are some “dominant" countries, yet the values are not so high to be significant.

It is also interesting revealing the different mentions to relevant keywords in the articles. Intuitively, the most relevant keywords are related to the COVID-19 and so we observe "Covid-19" (11 mentions) "pandemic" (5 mentions) and "Coronavirus" (3 mentions), "Health" and "SARS Cov-2" (2 mentions) each. It is worth to notice the results robustness: we obtain from the keyword-plus analysis a very similar output. The first keyword, in this case, is "Coronavirus Disease 2019" (3 mentions) "Pandemic" (3 mentions) and then a cohort of other keywords, each one mentioned 2 times.

The analysis of the network is represented in figure $\mathbf{3}$, which sketches the visualisation of the different concepts obtained. From figure 3, we observe a very dense network and, at the same time, the most central keywords of the entire network. Therefore, it is possible to analyse the network more in detail. From the network statistics, we are able to understand the relevant features of the literature considering the occurrences between the different keywords. 
The number of keywords studied in the network is 94 . The network can be considered dense being the keywords density 0.383 . Their transitivity is 0.859 , the diameter is 2 , the degree centralisation is 0.488 and the average path length is 1.506 .

At this point, we can figure out the specific centrality structure of the network by analysing the centrality. The two different centrality indexes show different characteristics since they confirm the same results. These indexes tend to have the same results. The correlation of the two sorting measures is 0.64 , showing a higher level of association between the two measures. This could be interpreted with the fact the network structure propends to be central and the different nodes that have a higher degree. For this reason, their trend is more locally-centred on the network and tend to the centre once examining the entire network structure. These nodes can be assessed as the most central and prominent ones of the entire network.

The nodes which show the highest centrality are the following keywords: "Coronavirus disease 2019”, “pandemic”, “public health”, “article”, “economic aspect” and finally "human”. These nodes are those which show higher prominence on the network, so they shall be the most pertinent topics to be considered for future research because these topics seem to be the most interesting ones for the authors involved in this literature. These nodes also indicate the importance of LCA analyses associated with these relevant themes in the literature. Following Kumar et al. (2020), LCA is deemed to be a relevant tool, used with the aim to identify the environmental effects and materials used in the product's life cycle. The considered phases start from the acquisition of raw materials and arrive at the waste management. In this respect, LCA allows the measurement of the aggregate and the substantial environmental impacts of products considering all the product life cycle phases.

Kumar et al. (2020) say that in the context of the pandemic, the PPE (Personal Protective Equipment) kits have increased in clinics and other healthcare facilities intending to minimize viral infections. In this context, the PPE kits that may be extremely hazardous must be treated and disposed of appropriately to prevent public health, land, and marine environments from being polluted (in our 
analysis "environmental factor" and "public health"). The authors conclude that decentralised incineration has been recognised as an environmentally sustainable management choice in contrast with the centralised incinerator. The effect of transportation is also essential and often ignored. So considering this context, the author reputes relevant to explore and promote decentralised disposal strategies, namely a source of successful waste management, recognising various crucial elements as handling, storage, or risks connected to transportation (Kumar et al. 2020).

These nodes also indicate the centrality of concepts connecting with COVID-19, Environment and Economy. This paves the way for the investigation of the social dimension of the crisis. Importantly, the UN (2021) repute that COVID-19 is concurrently a health crisis, a public health tragedy, and an economic crisis (but also a humanitarian disaster, a crisis of human rights and stability). The economic crisis has heavily impacted the economic systems determining a worsened recession. This crisis has also determined increased poverty and inequality rates. Following the UN (2021), the analysis of the social dimension is particularly relevant in Latin America and in the Caribbean. Deforestation and changes in land-use have been growing in this region (yet there are lower emissions). In addition, this area has shown to be extremely vulnerable to extreme weather events and natural hazards and major events caused or exacerbated by climate change - leading to worsened climate justice (Cisco and Gatto, 2021).

The final analysis is conducted to extrapolate the community structure of the network. The final analysis is conducted to extrapolate the community structure of the network and evaluating its stability and significance. In this respect, it is necessary to evaluate if the community structure detected by the algorithms used is just a consequence of chance or is statistically significant (Carissimo et al., 2018). From the "walktrap" algorithm we are able to detect 4 communities observing the whole network structure. The different communities are presented on their keywords members in Appendix. The different communities show different patterns of centrality. Community 1 is the most central amongst the other three and represents all the relevant themes in this literature. 
288 Community 2 shows the relevant biological and medical concepts which can be impacted by the virus 289 and successively community 3, are connected with the role of international institutions and their key 290 position in disease prevention. Finally, community 4 can be interpreted as an interesting category: it 291 mixes aspects that are intertwined with the environment, health care and health insurance. This aspect 292 can be of interest because represents a marginal topic as a group of keywords in the network which 293 can have some great potentialities to increase.

294 All the findings are sketched in table 1 and table 2.

295295

Figure 2: Structural analysis

296296

297297

298298

299299

300300

301301

302302

303303

304304

305305

The results are used to interpret the different communities extracted

306306

307307

308 Uncertainty analysis: Coronavirus or Covid-19 and aspects of life 
The query was performed on the Scopus database. The results are compared with the initial bibliometric results. We replicate all the analyses we have already performed with the goal to evaluate the relationship between Covid-19 and lifestyle. It is interesting to note that the lifestyle is also present in the communities related with the first analysis and there was associated with aspects as "chronic disease" and "immune-deficiency", "immune system" and "vulnerable population" (community 2). These aspects link relevant concepts as vulnerability to the lifestyles.

It is possible to investigate more in detail the aspects of lifestyle which are investigated in this literature. On the second community detection performed using the second bibliometric analysis, we found two communities: in the first one we found concepts as "oxygen therapy", "quarantine" and "virus transmission", whereas in the second one we found as relevant words "pandemic", "coronavirus infections" and "disease transmission" "infection control" and "practice guideline". Following Carissimo et al. (2008) also in this case, testing the significance of the identified community structure we can conclude, this is not a simple outcome due to chance (figure 7).

The results can be summarised interpreted through the lens of the following works: Acter et al. (2020), Sharfuddin (2020) and D'Adamo et al. (2020). Examining the short run, the keywords extracted show that the literature pivots around potential ways of controlling the infection by Coronavirus disease. In this respect, the focus is on aspects related to lifestyle. These considerations are related both to normal life as rules to avoid disease transmission, but also key rules related the medical practice (for a general overview see Acter et al. 2020, and Ali and Alharbi 2020). Lifestyle also includes nutrition, which is strictly intertwined with environmental quality and health (Agovino et al., 2018).

The publications also stress the importance of preventive measures - for instance, the role of hygiene and sanitation on the spread of Coronavirus disease. These are quite relevant in determining correct lifestyles against Covid-19. This is the case for "washing hands" (one of the relevant extracted keywords from the community) and in general careful hygienic measures (keeps hands away from eyes, mouth and nose), that seem to be amongst the compelling measures to avoid the virus 
transmission. Similarly, time, social distance and an attentive lifestyle oriented to avoid crowds constitute additional measures to be contemplated.

The emerging scholarship also highlights the symptomatology of Covid-19 which needs to be carefully checked to allow prompt medical response useful to avoid the virus transmission. Measures and prophylaxes such as "quarantine" and "social isolation" (community 1 in the second bibliometric analysis performed) can be considered determinant to avoid the spread of the virus.

Environmental factors are crucial factors also when it comes to lifestyles. A decisive research point discovered concerns whether the seasons and the meteorological conditions can have an impact on the disease spread. This implies that lifestyles should be addressed to minimise the risk of transmission of the disease in every climatic situation. A case study can be heating: "artificial ventilation" and "air conditioning system" should be carefully evaluated and a "respiratory etiquette" maintained in closed spaces (see Lu et al, 2020 regarding the role of air conditioning in expediting the spread of disease to populations). Respiratory etiquette is another relevant behaviour in modern lifestyles - for instance, coughing or sneezing into the elbow or arm (as "preventive measures" in community 1 of the first community in the additional bibliometric analysis - see also Zayas et al. 2020).

The virus outbreak has had an impact on lifestyle, affecting the daily lives of millions of people. In fact, the pandemic determined, in the short run, massive job losses, whereby entire economic sectors and businesses have experienced severe damages, shut down and even bankruptcy (Saadat et al. 2020). Conversely, this situation determined, in the short term, reduced water pollution and improved air quality. Nevertheless, this evidence needs to be evaluated considering the long-run and the disruptive impact of Covid-19 on the economy as we have observed on the main bibliometric analysis performed. The reduced water pollution, the improved air quality and in general the lower impact on the ecosystems and climate change lead to changes in behaviour not only in humans but also in other beings on the planet, in the whole ecosystem and in diverse complex systems (see Paital 2020). 
360 In this work, we have dealt with bibliometric techniques with the scope to extract prime findings on 361 the intersection literature on the 2019 Coronavirus, the economy and the environment. The analysis 362 aimed to extract the most pertinent semantic cores (see Drago and Hoxhalli 2020). The use of the semantic core aimed at the identification of the foremost groups of keywords within the publications for detecting the literature development.

Bibliometric techniques (see Su et al. 2020, and Drago and Amidani Aliberti 2018) had relevant applications in the study of the Coronavirus and Environmental Sciences (John et al. 2020, Lou et al. 2020). Amongst the advantages of the bibliometric techniques, it is paramount the capability to allow the synthesis and the analysis of many scientific works and results. This approach can be usefully applied to the analysis of the literature on environmental and economic issues related to the Coronavirus.

Secondarily, another important piece of information provided by bibliometrics is to allow some replaceable analysis and metrics whilst investigating some of the most relevant literature findings. More particularly, a bibliometric analysis allows assessing quantitative research, identifying the most cited works and authors. This methodology permits to identify of the most relevant publication topics, productive countries and patterns of scientific cooperation - responding to specific needs. Mapping related scholarship, bibliometrics considers the co-occurrence amongst existing keywords, with the aim to study the most relevant topics and their relationships.

The work presents some elements of novelty: it combines the existing literature to find meaningful results from the previous findings in the existent one. The bibliometric studies and the literature reviews are very relevant nowadays because they allow the combination and synthesis of the current results. Simultaneously, these methodologies allow a better understanding of the relationships between relevant concepts and themes. Following Ziegler (2009), the classification and arrangement of information is the aim of the field of library and information science. Bibliometrics is fundamental 
to analyse the different interlinkages between multiple fields and topics. By considering the citations mentioned in each series of articles, bibliometrics may also be used to evaluate a specific article's relevance to a particular field.

As limitations, bibliometric techniques do not necessarily cover all existing articles - for instance, it does not include grey literature. Another limitation is that bibliometrics tends to take in to account the scientific literature published in English with respect to papers published in other languages. Lastly, citations are not necessarily associated with quality (Wallin 2005). The relationship between quality and citation can largely deviate. Further criticisms exist when using bibliometric techniques: primarily, it does not necessarily exist a statistical relationship between quality and citations. So from one side, it is possible to observe that bibliometric indicators do not necessarily synthesise the "impact of an article" or the "impact of a piece of research", as a latent concept which is multidimensional by nature and so it is difficult to be measured (see Haustein and Lariviere 2015). Finally, non-scientific reasons can motivate the different citations behaviours. In this sense, research findings often show other variables - partly non-scientific - which play a role in the citation decision (see Bornmann and Daniel, 2008). So the networks of co-citations cannot reflect "true" representation of the existing scientific linkages and references. The results indicate wide room for improvements on these topics. We found evidence of possible gaps in this literature due to the fact we obtained different communities. Furthermore, some interesting topics seem not to be fully covered. Another main finding is that the journals in the investigated research field - the closest to Environmental Economics - show a higher level of fragmentation: every journal has published on these topics at maximum one article (with the exception of the Journal of Business Research with two publications). The trendiest topics are connected with the Coronavirus (or COVID-19 or Covid) and health. Also in this case, it is remarkable the existence of various possibilities to consider new topics and streams of research related to the environment which are not considered in this literature. We can conclude that the 
network analysis, and more importantly the community detection, is determinant to show prior features of the inspected literature.

The outputs suggest that the primary nodes of networks are informative for detecting the relevant literature gaps. The journals show higher fragmentation so they are not that relevant to show some particular pattern. Conversely, the topics result of primary importance. This implies that this result is rendered via the comparison of the community detection exercise with the structural analysis outputs. This conclusion allows extrapolating the most central keywords within the network. Intuitively, these are related to the Coronavirus. We also appreciate major interconnections with nodes that are related to economic activity.

Selected Environmental Economics implications arise. Where the economic impact of the Coronavirus is tremendous, the impact on the global environment should be investigated (Bateman et al. 2020). In this respect, it is necessary to follow the reasoning of Helm (2020) and exploring the environmental impacts of the COVID-19. These pieces of evidence are also related to the fact that policies were usually directed on the containment of the spread of the outbreak. Evaluating a higher range of impacts on the environment, it could be necessary to consider sound policies (OECD 2020).

In order to analyse and discover holes in the literature, we tried to investigate the nodes or keywords - namely, the members of the different communities extracted. More precisely, the approach is based on identifying the communities and then testing the stability of the communities found. Following Carissimo et al. (2018), we test the significance of the detected communities against random perturbation of the network's initial structure. The computational procedure makes it possible to conclude on the test whether there is a significant difference from the considered null model. The results are represented in figure 4,5 , and 6 , where we found the significance of the three identified communities. That means a relevant semantic core on the topic, represented by the considered interconnections of the co-occurrences, has been identified. 
We found a set of co-occurrence communities that allow network decomposition. The first one relates to the management of the emergence and focuses on the control of the disease spread, public health, the environment and also the economic impact. The other communities are connected with lifestyle and prevention of the disease, the role of education and also the importance of regulation in the long run. The test allows concluding that these identified communities or semantic cores are statistically significant and are not an effect. The procedures quantify where the clustering results obtained differs significantly from the null hypothesis (or the null model, see Carissimo et al., 2018).

The first community can be interpreted as the one referring to health and environmental aspects on the one hand and the longer-term economic ones on the other. The second community can be conceived as the relationships between health and lifestyles. The third one focuses on the role of education in the prevention of disease transmission. Lastly, the fourth community stresses the role of regulation on disease prevention.

A first relevant point regarding the first community is the relevance of the "environmental factor" in relation to the Coronavirus or the "disease spread". To this end, resource sustainability, vulnerability and resilience result crucial for environmental quality (Gatto and Busato, 2020; Gatto and Drago, 2020b). Various environmental factors can be considered relevant, for instance, climate and weather (Shi et al. 2020). Another important "risk factor" (as a relevant keyword identified) is air pollution (Martelletti and Martelletti 2020). Following Barceló (2020), air quality seems to be highly relevant to the "Coronavirus infection".

The themes on community 1 define in detail the aspects interconnected with the disease spread and their dynamics that are associated with important risk factors as environmental factors. In line with Barceló (2020), we find a mixture of different keywords related to the population ("population growth", "population risk"), the meteorological factors, linked also to mobility ("migration") could be interpreted as key elements in the articles covering the Covid-19 spread of the disease ("disease transmission"). 
To match this scope, we identify a group showing an intriguing relationship, being part of the same group of relevant nodes as "environment", "health care need" and "law". Where these nodes are not central considering in the centrality indexes, we can conclude that they are not only interesting due to the specific innovative research topic they show - they are indicative of the modality of how to manage the regulation attached to the environment and health care need. This is a significative piece of scientific novelty, signalling the transition from the mere impact notification towards the indications on how to manage the impact, paving the way for paramount public health and environmental health advances.

SARS-CoV-2 induced significant changes in lifestyle and behaviour - not only in humans but also in other living beings on the planet, the whole ecosystem and complex systems. Starting from the result in community 2 , in order to provide an overarching understanding of the problem and potential solutions, we have also investigated aspects of life as part of the keywords extracted. In order to explore more in-depth the aspects related to lifestyle as additional exploratory analysis, we perform a second bibliometric analysis considering Coronavirus or Covid-19 and aspects of life.

Overall, in the long run, relevant economic and social aspects emerge (business management and overall economic). These are accompanied by broad environmental topics which are also connected with health issues. These results complete the analysis we have performed and clarify initial results: the economic aspects are paramount to manage and sustain the social systems, but lifestyles have been dramatically affected and drastically changed by SARS-CoV-2. The latter represents potentially a striking result to be managed at a macro level.

These changes relate to various aspects of life - for instance, the control of the infection, the measures against the transmission of the disease but also the medical practice. Similarly, the health and environmental risk factor can decisively impact disease transmission and pandemic. This is why, in the long run, lifestyles, health and environmental issue, along with economic aspects, should be carefully managed both at a national and international level. 
482 The finding signals a major gap in the literature that needs to be considered for the future. The 483 usefulness of the results is that these signals allow to summarise the most relevant core themes in 484 literature but also to identify the most relevant relationships between the different considered themes. 485 Future international research can usefully explore additional key-themes departing from the relevant 486 semantic-cores, which are the most structured publications on the topic.

487 As a limitation and incentive for proceeding with future studies in these streams of research, a typical 488 technique adopted in bibliometrics may be exploited - that is the use of various keywords. The latter 489 method can resemble the network analysis and returns more detailed information on the concepts 490 studied as literature topics. 
492

493

494

495

496

497

498

499

500

501

502

503

504

505

506

507

508

509

510

511

512

513

Acter, T., Uddin, N., Das, J., Akhter, A., Choudhury, T. R., \& Kim, S. (2020). Evolution of severe acute respiratory syndrome coronavirus 2 (SARS-CoV-2) as coronavirus disease 2019 (COVID-19) pandemic: A global health emergency. Science of the Total Environment, 138996.

Agovino, M., Cerciello, M., \& Gatto, A. (2018). Policy efficiency in the field of food sustainability. The adjusted food agriculture and nutrition index. Journal of environmental management, 218, 220233.

Ali, I., \& Alharbi, O. M. (2020). COVID-19: Disease, management, treatment, and social impact. Science of the Total Environment, 138861.

Aria, M. \& Cuccurullo, C. (2017) bibliometrix: An R-tool for comprehensive science mapping analysis, Journal of Informetrics, 11(4), pp 959-975, Elsevier.

Bader, D. A., Kintali, S., Madduri, K., \& Mihail, M. (2007, December). Approximating betweenness centrality. In International Workshop on Algorithms and Models for the Web-Graph (pp. 124-137). Springer, Berlin, Heidelberg.

Bandala, E. R., Kruger, B. R., Cesarino, I., Leao, A. L., Wijesiri, B., \& Goonetilleke, A. (2021). Impacts of COVID-19 pandemic on the wastewater pathway into surface water: A review. Science of The Total Environment, 145586.

Barceló, D. (2020). An environmental and health perspective for COVID-19 outbreak: Meteorology and air quality influence, sewage epidemiology indicator, hospitals disinfection, drug therapies and recommendations. Journal of Environmental Chemical Engineering, Aug; 8(4): 104006.

Bateman, I. J., Neetzow, P., Eisenack, K., \& Meran, G. (2020). EAERE, ERE and the Research Challenges of the Coronavirus Pandemic. Environmental \& Resource Economics, 1.

Borgatti, S. P. (2005). Centrality and network flow. Social networks, 27(1), 55-71. 
Bornmann, L., \& Daniel, H. D. (2008). What do citation counts measure? A review of studies on citing behavior. Journal of documentation.

Carissimo, A., Cutillo, L., \& De Feis, I. (2018). Validation of community robustness. Computational Statistics \& Data Analysis, 120, 1-24.

Chakraborty, I., \& Maity, P. (2020). COVID-19 outbreak: Migration, effects on society, global environment and prevention. Science of the Total Environment, 138882.

Cisco, G., \& Gatto, A. (2021). Climate Justice in an Intergenerational Sustainability Framework: A Stochastic OLG Model. Economies.

Csardi G, Nepusz T (2006) The igraph software package for complex network research, InterJournal, Complex Systems 1695. http://igraph.org

D'Adamo, H., Yoshikawa, T., \& Ouslander, J. G. (2020). Coronavirus disease 2019 in geriatrics and long- term care: the ABCDs of COVID- 19. Journal of the American Geriatrics Society, 68(5), 912917.

Drago C (2017). MCA Based Community Detection. Classification, (Big) Data Analysis and Statistical Learning. In: (a cura di): Francesco Mola, Claudio Conversano, Maurizio Vichi, Classification, (Big) Data Analysis and Statistical Learning. Studies in Classification, Data Analysis and Knowledge.

Drago C., Amidani Aliberti L. (2018) "Interlocking Directorship Networks and Gender: a Bibliometric Analysis Advances in Gender and Cultural Research in Business and Economics: 4th Ipazia Workshop on Gender Issues 2018, Rome, Italy

Drago C, Balzanella A (2015). Nonmetric MDS consensus community detection. In: (a cura di): Minerva T., Morlini I., Vichi M., Studies in Classification, Data Analysis, and Knowledge 
536 Organization. Studies in Classification, Data Analysis, and Knowledge Organization, vol. 50, p. 97 537 105, Kluwer Academic Publishers,

538 Drago C. Ricciuti R. (2017) Communities detection as a tool to assess a reform of the Italian 539 interlocking directorship network Physica A: Statistical Mechanics and its Applications 466, 91-104

540 Drago C. Hoxhalli G. (2020) Bibliometric Big Data Analysis in Economics. Conference: IFKAD 5412020 "Knowledge in Digital Age" Rome, Italy 9-11 September 2020

542 El Mohadab, M., Bouikhalene, B., \& Safi, S. (2020). Bibliometric method for mapping the state of 543 the art of scientific production in Covid-19. Chaos, Solitons \& Fractals, 139, 110052.

544 Falagas, M. E., Pitsouni, E. I., Malietzis, G. A., \& Pappas, G. (2008). Comparison of PubMed, 545 Scopus, web of science, and Google scholar: strengths and weaknesses. The FASEB journal, 22(2), $546 \quad 338-342$.

547 Fernandes, N. (2020). Economic effects of coronavirus outbreak (COVID-19) on the world economy. 548 Available at SSRN 3557504.

549 Fortunato, S., \& Castellano, C. (2007). Community structure in graphs. arXiv preprint 550 arXiv:0712.2716.

551 Fortunato, S. (2010). Community detection in graphs. Physics reports, 486(3-5), 75-174.

552 Gatto, A., \& Busato, F. (2020). Energy vulnerability around the world: The global energy 553 vulnerability index (GEVI). Journal of Cleaner Production, 253, 118691.

554 Gatto, A., \& Drago, C. (2020a). A taxonomy of energy resilience. Energy Policy, 136, 111007.

555 Gatto, A., \& Drago, C. (2020b). Measuring and modeling energy resilience. Ecological Economics, $556172,106527$. 
557 Gatto, A., Drago, C., \& Ruggeri, M. (2020). On the frontline-Sustainability and development 558 research amidst the COVID-19 pandemic. Under review, World Development.

559 Haustein, S., \& Larivière, V. (2015). The use of bibliometrics for assessing research: Possibilities, 560 limitations and adverse effects. In Incentives and performance (pp. 121-139). Springer, Cham.

561 The Lancet Digital Health (2021). Technology: the nexus of climate change and COVID-19?.Helm, 562 D. (2020). The environmental impacts of the coronavirus. Environmental \& Resource Economics, 1. 563 Ho, Y. S, \& Gatto, A. (2020). A Bibliometric Analysis of COVID-19 Research. Under review, 564 Nature.

565 Homolak, J., Kodvanj, I., \& Virag, D. (2020). Preliminary analysis of COVID-19 academic 566 information patterns: a call for open science in the times of closed borders. Scientometrics, 1-15.

567 John, I., Kwofie, E.M. \& Ngadi, M. Two decades of eco-efficiency research: a bibliometric 568 analysis. Environmental Sustainability 3, 155-168 (2020). https://doi.org/10.1007/s42398-020$569 \quad \underline{00105-1}$

570 Kumar, H., Azad, A., Gupta, A., Sharma, J., Bherwani, H., Labhsetwar, N. K., \& Kumar, R. (2020). 571 COVID-19 Creating another problem? Sustainable solution for PPE disposal through LCA 572 approach. Environment, Development and Sustainability, 1-15.

573 Kurian, M. (2017). The water-energy-food nexus: trade-offs, thresholds and transdisciplinary 574 approaches to sustainable development. Environmental Science \& Policy, 68, 97-106.

575 Lancichinetti, A., \& Fortunato, S. (2009). Community detection algorithms: a comparative 576 analysis. Physical review E, 80(5), 056117.

577 Liu, J., Hull, V., Godfray, H. C. J., Tilman, D., Gleick, P., Hoff, H., ... \& Li, S. (2018). Nexus 578 approaches to global sustainable development. Nature Sustainability, 1(9), 466-476. 
579 Lou, J., Tian, S. J., Niu, S. M., Kang, X. Q., Lian, H. X., Zhang, L. X., \& Zhang, J. J. (2020). 580 Coronavirus disease 2019: a bibliometric analysis and review. Eur Rev Med Pharmacol Sci, 24(6), $581 \quad 3411-21$.

582 Lu, J., Gu, J., Li, K., Xu, C., Su, W., Lai, Z., ... \& Yang, Z. (2020). COVID-19 outbreak associated 583 with air conditioning in restaurant, Guangzhou, China, 2020. Emerging infectious diseases, 26(7), 5841628.

585 Martelletti, L., \& Martelletti, P. (2020). Air pollution and the novel Covid-19 disease: a putative 586 disease risk factor. SN Comprehensive Clinical Medicine, 1-5.

587 OECD (2020) "From containment to recovery: Environmental responses to the COVID-19 588 pandemic" version 20 April 2020 http://www.oecd.org/coronavirus/policy-responses/from589 containment-to-recovery-environmental-responses-to-the-covid-19-pandemic-92c49c5c/ accessed 590 the $12 / 6 / 2020$.

591 Paital, B. (2020). Nurture to nature via COVID-19, a self-regenerating environmental strategy of 592 environment in global context. Science of The Total Environment, 139088.

593 Pons, P., Latapy, M. (2005) Computing communities in large networks using random walks. In: 594 Yolum, p., Güngör, T., Gürgen, F., Özturan, C. (eds.) ISCIS 2005. LNCS, vol. 3733, pp. 284-293. 595 Springer, Heidelberg.

596 Saadat, S., Rawtani, D., \& Hussain, C. M. (2020). Environmental perspective of COVID-19. Science 597 of The Total Environment, 138870.Sharfuddin, S. (2020). The world after covid-19. The Round 598 Table, 109(3), 247-257.

599 Sharifi, A., \& Khavarian-Garmsir, A. R. (2020). The COVID-19 pandemic: Impacts on cities and 600 major lessons for urban planning, design, and management. Science of the Total Environment, $601 \quad 142391$. 
602

603

604

605

606

607

608

609

610

611

612

613

614

615

616

617

618

619

620

621 622 COVID-19 on the environment. Science of the Total Environment, 728, 138813.

Shi, P., Dong, Y., Yan, H., Li, X., Zhao, C., Liu, W., ... \& Xi, S. (2020). The impact of temperature and absolute humidity on the coronavirus disease 2019 (COVID-19) outbreak-evidence from China. MedRxiv.

Su, Y., Yu, Y., \& Zhang, N. (2020). Carbon emissions and environmental management based on Big Data and Streaming Data: A bibliometric analysis. Science of The Total Environment, Volume 733, 1 September 2020, 138984.

UN News (2020). "Urgency to act' for sustainable development, greater than ever as coronavirus pandemic continues" https://news.un.org/en/story/2020/05/1063742 page accessed the 12/6/2020

UN (2021). "High Level Session: The Environmental Dimension of COVID-19 Sustainable Development Recovery” XXII Meeting of the Forum of Ministers of Environment of Latin America and the Caribbean Bridgetown, Barbados 1-2 February 2021

Van Eck, N.J., \& Waltman, L. (2014). Visualizing bibliometric networks. In Y. Ding, R. Rousseau, \& D. Wolfram (Eds.), Measuring scholarly impact: Methods and practice (pp. 285-320). Springer.

Wallin, J. A. (2005). Bibliometric methods: pitfalls and possibilities. Basic \& clinical pharmacology \& toxicology, 97(5), 261-275.

Wasserman, S., \& Faust, K. (1994). Social network analysis: Methods and applications (Vol. 8). Cambridge university press.

WHO (2020) “COVID 19 Strategy Update” file:///C:/Users/Unicusano\%20admin/Downloads/covidstrategy-update-14april2020.pdf accessed 12/6/2020

21 Zambrano-Monserrate, M. A., Ruano, M. A., \& Sanchez-Alcalde, L. (2020). Indirect effects of 
623 Zayas, G., Chiang, M. C., Wong, E., MacDonald, F., Lange, C. F., Senthilselvan, A., \& King, M. 624 (2013). Effectiveness of cough etiquette maneuvers in disrupting the chain of transmission of 625 infectious respiratory diseases. BMC Public Health, 13(1), 811.

626 Ziegler, B. E. (2009). Methods for bibliometric analysis of research: renewable energy case 627 study (Doctoral dissertation, Massachusetts Institute of Technology). 
628 Appendix

629 Table 1. Statistical analysis of the literature

630 \$MainInformationDF

631

Description Results

6321

Documents $\quad 15$

6332

Sources (Journals, Books, etc.)

6343

Keywords Plus (ID)

94

6354

Author's Keywords (DE)

86

6365

Period 2020 - 2020

637

Average citations per documents

0.1333

638

Authors

110

6398

Author Appearances

110

640

Authors of single-authored documents

64110 Authors of multi-authored documents

642

Single-authored documents

$643 \quad 12$

Documents per Author

0.136

$644 \quad 13$

Authors per Document

7.33

$645 \quad 14$

Co-Authors per Documents

7.33

$646 \quad 15$

Collaboration Index

8.92

$647 \quad 16$

$648 \quad 17$

Document types

$649 \quad 18$

ARTICLE

12

$650 \quad 19$

CONFERENCE PAPER 
$\begin{array}{llll}656 & 1 & 2020 & 15\end{array}$

657

658 \$AnnualGrowthRate

$659 \quad[1] \quad 0$

660

661 \$MostProdAuthors

662

Authors

Articles Authors

6642 ALI H

6653 ALLAM Z

6664 ASCHNER M

6675 ASHIRU-OREDOPE D

6686 BABAR ZUD

6697 BEDFORD J

6708 BOONYABANCHA S

6719 CALINA D

67210 CHAKRABORTY I

673

674 \$MostCitedPapers

675
1 EGGERS F

1.000

Articles Fractionalized

1 SICHE R

1.000

1 USHKALOVA DI

1.000

1 ALLAM Z

0.500

1 CHAKRABORTY I

0.500

1 HEITMAN E

0.500

1 JONES DS

0.500

1 LITEWKA SG

0.500

1 MAITY P

0.500

1 DWIVEDI RK

0.333
TC TCperYear

6772 SICHE R, 2020, SCIENTIA AGROPECU

6783 ALLAM Z, 2020, LAND USE POLICY

6794 CHAKRABORTY I, 2020, SCI TOTAL ENVIRON

6805 WANG Y, 2020, J BUS RES

0


6816 EGGERS F, 2020, J BUS RES

6827 TSATSAKIS A, 2020, FOOD CHEM TOXICOL 0

6838 CHAN AHY, 2020, J PHARM POLICY PRACT 0

6849 MAHTO G, 2020, INT J ADV SCI TECHNOL 0

68510 EL ZOWALATY ME, 2020, INFECT ECOL EPIDEMIOL 0 o

686

687 \$MostProdCountries

688 Country Articles Freq SCP MCP MCP_Ratio

$689 \quad 1$ INDIA $\quad 20.333 \quad 2 \quad 0 \quad 0$

$690 \quad 2$ CHINA $\quad 10.167 \quad 1 \quad 000$

6913 PERU $\quad 10.167 \quad 1 \quad 00$

6924 USA $\quad 10.167 \quad 1 \quad 00$

6935 VIETNAM $\quad 10.167 \quad 0 \quad 1 \quad 1$

694

695 \$TCperCountries

696 Country Total Citations Average Article Citations

6971 PERU $\quad 1 \quad 1$

$\begin{array}{lllll}698 & 2 & \text { VIETNAM } & 1 & 1\end{array}$

6993 CHINA $\quad 0 \quad 0$

$\begin{array}{llll}700 & 4 & \text { INDIA } & 0\end{array}$

$\begin{array}{lllll}701 & 5 & \text { USA } & 0 & 0\end{array}$

702

703 \$MostRelSources

704

Sources Articles

7051 JOURNAL OF BUSINESS RESEARCH

7062 CYTOKINE AND GROWTH FACTOR REVIEWS

7073 DEVELOPING WORLD BIOETHICS 
7106 INFECTION ECOLOGY AND EPIDEMIOLOGY

7117 INTERNATIONAL JOURNAL OF ADVANCED SCIENCE AND TECHNOLOGY

7128 INTERNATIONAL JOURNAL OF PSYCHOSOCIAL REHABILITATION

7139 JOURNAL OF PHARMACEUTICAL POLICY AND PRACTICE

71410 LAND USE POLICY

715

716 \$MostRelKeywords

717 Author Keywords (DE) Articles Keywords-Plus (ID) Articles

7192 PANDEMIC 5 PANDEMIC 3

$\begin{array}{llll}720 & 3 & \text { CORONAVIRUS } & 3 \text { ARTICLE }\end{array}$

$721 \quad$ HEALTH 2 ECONOMIC ASPECT

$722 \quad 5$ SARS COV 22 EPIDEMIC

$72362019 \mathrm{NCOV} \quad 1$ GLOBAL HEALTH

$\begin{array}{llll}724 & 7 & \text { AGRICULTURE } & 1 \\ & \text { HUMAN } & 2\end{array}$

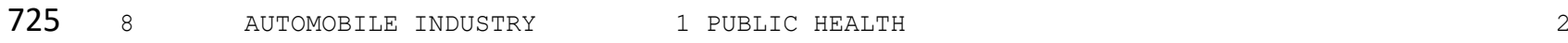

7269 BAYESVL 1 RISK FACTOR

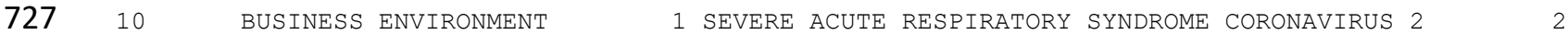

728 


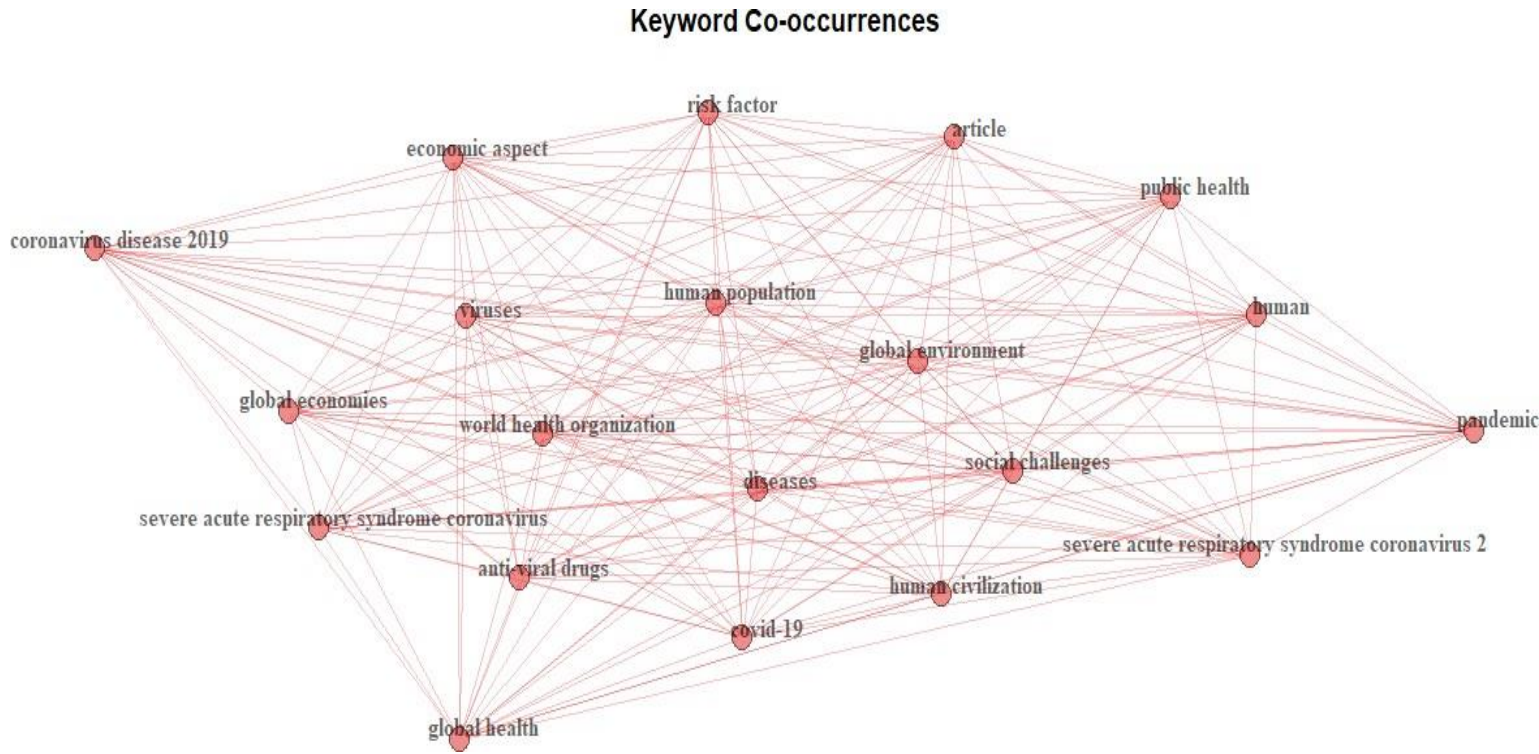

731 Main statistics about the network

732

Table 2. Network statistics

733

734 
747 HUMAN

748 RISK FACTOR

749 SEVERE ACUTE RESPIRATORY SYNDROME CORONAVIRUS 2

750 GLOBAL HEALTH

771 [4] "GLOBAL ENVIRONMENT" 
$781[14]$ "HEALTH IMPACT"

782 [15] "HEALTH RISK"

783 [16] "PUBLIC HEALTH"

784 [17] "RESPIRATORY DISEASE"

785 [18] "VIRAL DISEASE"

786 [19] "ARTICLE"

787 [20] "CORONAVIRUS DISEASE 2019"

788 [21] "CORONAVIRUS INFECTION"

789 [22] "DISEASE TRANSMISSION"

790 [23] "ECONOMIC ASPECT"

791 [24] "ENVIRONMENTAL FACTOR"

792 [25] "GLOBAL HEALTH"

$793[26]$ "HUMAN"

794 [27] "INFECTION CONTROL"

795 [28] "INFECTION PREVENTION"

796 [29] "INFECTION RATE"

797 [30] "MIGRATION"

798 [31] "PANDEMIC" 
799 [32] "POPULATION GROWTH"

800 [33] "POPULATiON RISK"

801 [34] "PRIORITY JOURNAL"

802 [35] "RISK FACTOR"

803 [36] "SEVERE ACUTE RESPIRATORY SYNDROME CORONAVIRUS 2"

804 [37] "CHINA"

$805[38]$ "HUBEI"

806 [39] "WUHAN"

807 [40] "CORONAVIRUS"

808 [41] "SARS CORONAVIRUS"

809

810

811 \$2

812 [1] "Angiotensin CONVERting Enzyme 2" "AROMAtic hydROCARbon ReCeptoR"

813

[3] "FOSSIL FUEL"

"HEAVY METAL"

814

[5] "MULti WALLEd NANOtUBe"

"PESTICIDE"

815

[7] "XENOBIOTIC AGENT"

"AIRBORNE PARTICLE"

816

[9] "BIOCHEMISTRY"

"BIOPHYSICS"

817

[11] "CELL FUnCtion"

"CELL LEVEL"

818 [13] "CHRONIC DISEASE"

"DIETARY SUPPLEMENT"

819

[15] "IMMUNE DEFICIENCY"

"IMMUNE SYSTEM"

820

[17] "Immunopathology"

"IMMUNOTOXICITY"

821 [19] "INTESTINE FLORA"

"IONIZING RADIATION"

822

[21] "LIfestyle"

"LONG TERM EXPOSURE"

823

[23] "MACROPHAGE"

"PARTICULATE MATTER"

824

[25] "POLLUTANT"

"PREVALENCE"

825

[27] "PROTEIN EXPRESSION"

"SIGNAL TRANSDUCTION" 
844 [1] "VIRUSES"

$845[2]$ "CORONAViRUSES"

846 [3] "GLOBAL HEALth"

847 [4] "INFECTIOUS DISEASE"

848 [5] "JOHNS HOPKINS UNIVERSITIES"

849 [6] "PREVENTIVE MEASURES"

850 [7] "RESEARCH ACTIVITIES"

851 [8] "SEVERE ACUTE RESPIRATORY SYNDROME CORONAVIRUS"

$852[9]$ "WUHAN"

853 [10] "CHINA"

854 [11] "DISEASES"

855 [12] "ANTIINFECTIVE AGENT"

856 [13] "ANTIPYRETIC AgENT" 
857 [14] "COVID-19"

858 [15] "DISEASE CONTROL"

859 [16] "DISEASE SPREAD"

860 [17] "EPIDEMIC"

861 [18] "SEVERE ACUTE RESPIRATORY SYNDROME"

862 [19] "VIRAL DISEASE"

863 [20] "ADULT RESPIRATORY DISTRESS SYNDROME"

864 [21] "ARTIFICIAL VENTILATiON"

865 [22] "CONTAMINAtion"

866 [23] "CORONAVIRUS DISEASE 2019"

867 [24] "DISINFECTION"

868 [25] "EMERGENCY"

869 [26] "ENVIRONMENTAl FACTOR"

870 [27] "EVolution"

871 [28] "FEVER"

872 [29] "GENE SEQUENCE"

873 [30] "GEOGRAPHIC DISTRIBUTION"

874 [31] "HAND WASHING"

875 [32] "HEALTH HAZARD"

876 [33] "HUMAN"

877 [34] "INFECTION PREVENTION"

878 [35] "NONHUMAN"

879 [36] "NUCLEIC ACID AMPLIFICATION"

880 [37] "OXYGEN THERAPY"

881 [38] "PRIORITY JOURNAL"

882 [39] "QUARANTINE"

$883[40]$ "REVIEW"

884 [41] "SEPSIS"

885 [42] "SEROLOGY"

886 [43] "SEVERE ACUTE RESPIRATORY SYNDROME CORONAVIRUS 2"

887 [44] "SOCIAL ISOLATION"

888 [45] "SYMPtomatology"

889 [46] "THORAX RADIOGRAPHY"

890 [47] "VIRUS PATHOgEnESiS"

891 [48] "VIRUS REPLICATION"

892 [49] "VIRUS TRANSMISSION"

893 [50] "WINTER" 


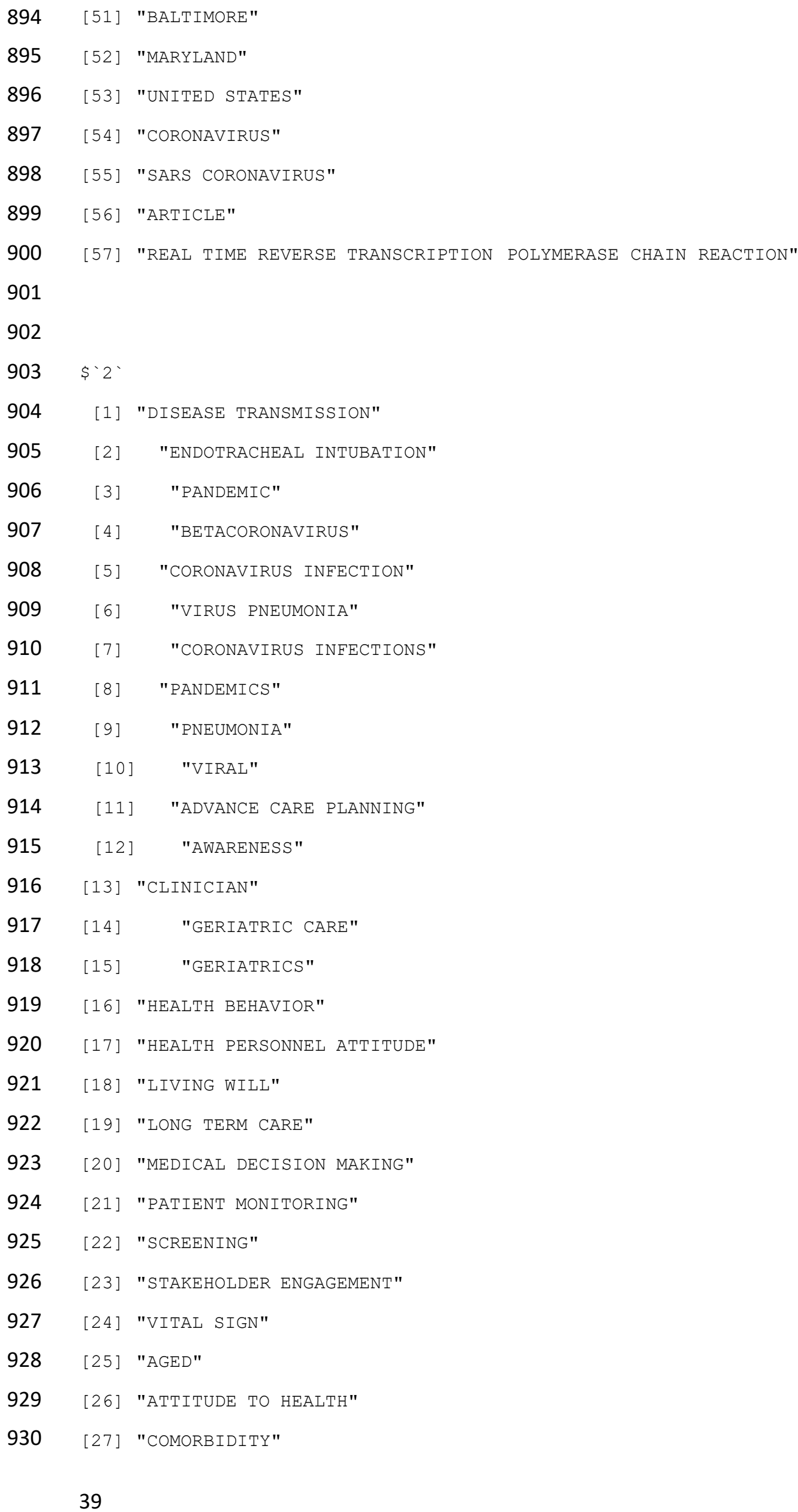


931 [28] "DECISION MAKING"

932 [29] "HEALTh CARE PERSONNEL"

933 [30] "INFECTION CONTROL"

934 [31] "PSYCHOLOGY"

935 [32] "RESIDENTIAL HOME"

936 [33] "RISK FACTOR"

937 [34] "HEALTH KNOWLEDGE"

938 [35] "Aтtitudes"

939 [36] "PRACTICE"

940 [37] "HEALTH PERSONNEL"

941 [38] "HUMANS"

942 [39] "LONG-TERM CARE"

943 [40] "RESIDENTIAL FACILITIES"

944 [41] "RISK FACTORS"

945 [42] "HEALth ImpACT"

946 [43] "HEALTH RISK"

947 [44] "PUBLIC HEALTH"

948 [45] "ADULT"

949 [46] "ANXIETY"

950 [47] "CLINICAL PROTOCOL"

951 [48] "CROSS-SECTIONAL STUDY"

952 [49] "DENTAL PRACTICE"

953 [50] "DENTIST"

954 [51] "FEAR"

955 [52] "FEMALE"

956 [53] "KNOWLEDGE"

957 [54] "MALE"

958 [55] "PRACTICE GUIDELINE"

959 [56] "PRIVATE HOSPITAL"

960 [57] "PUBLIC HOSPItAL"

961 [58] "CLINICAL PRACTICE"

962 [59] "CORONAVIRINAE"

963 [60] "MENTAL STRESS"

964 [61] "QUESTIONNAIRE"

965 [62] "CROSS-SECTIONAL STUDIES"

966 [63] "DENTISTS"

967 [64] "DISEASE OUTBREAKS" 
970 [67] "STRESS"

971 [68] "PSYCHOLOGICAL"

972 [69] "SURVEYS AND QUESTIONNAIRES"

973 [70] "BELGIUM"

974 [71] "END STAGE LIVER DISEASE"

975 [72] "LIVER TRANSPLANTATION"

976 [73] "DATA ANALYSIS"

977 [74] "MEDICAL EDUCATION"

978 [75] "NURSING EDUCATION"

979 [76] "EDUCATION"

980 [77] "NURSING"

981 [78] "FELLOWSHIPS AND SCHOLARSHIPS"

982 [79] "NURSING EDUCATION RESEARCH"

983

984

985

986

987

988

989

990

991

992

993

994

995

996

997

998

999

1000

1001

1002

1003

1004 


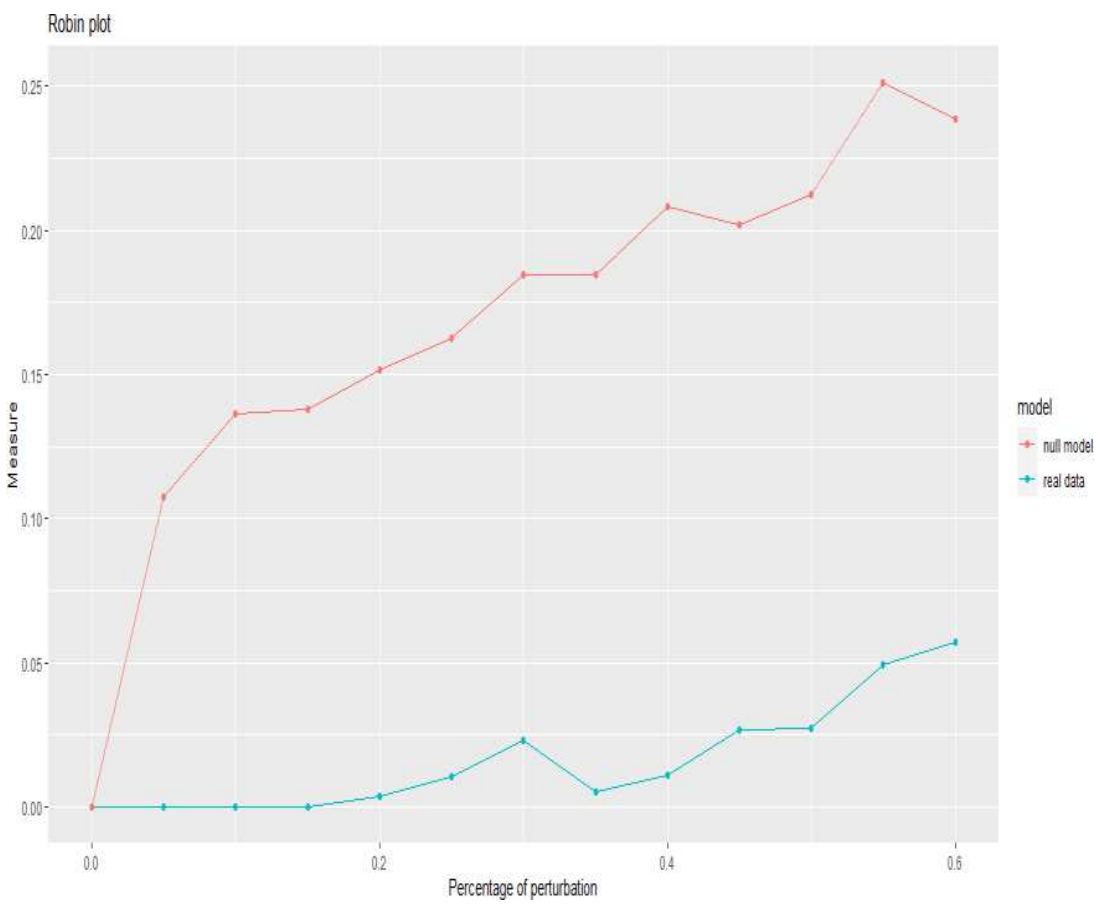

1008

1009 1010 1011

Figure 5: Keyword occurrences (keywords $n=20$ ) 1012 


\section{Measure : Functional Data}

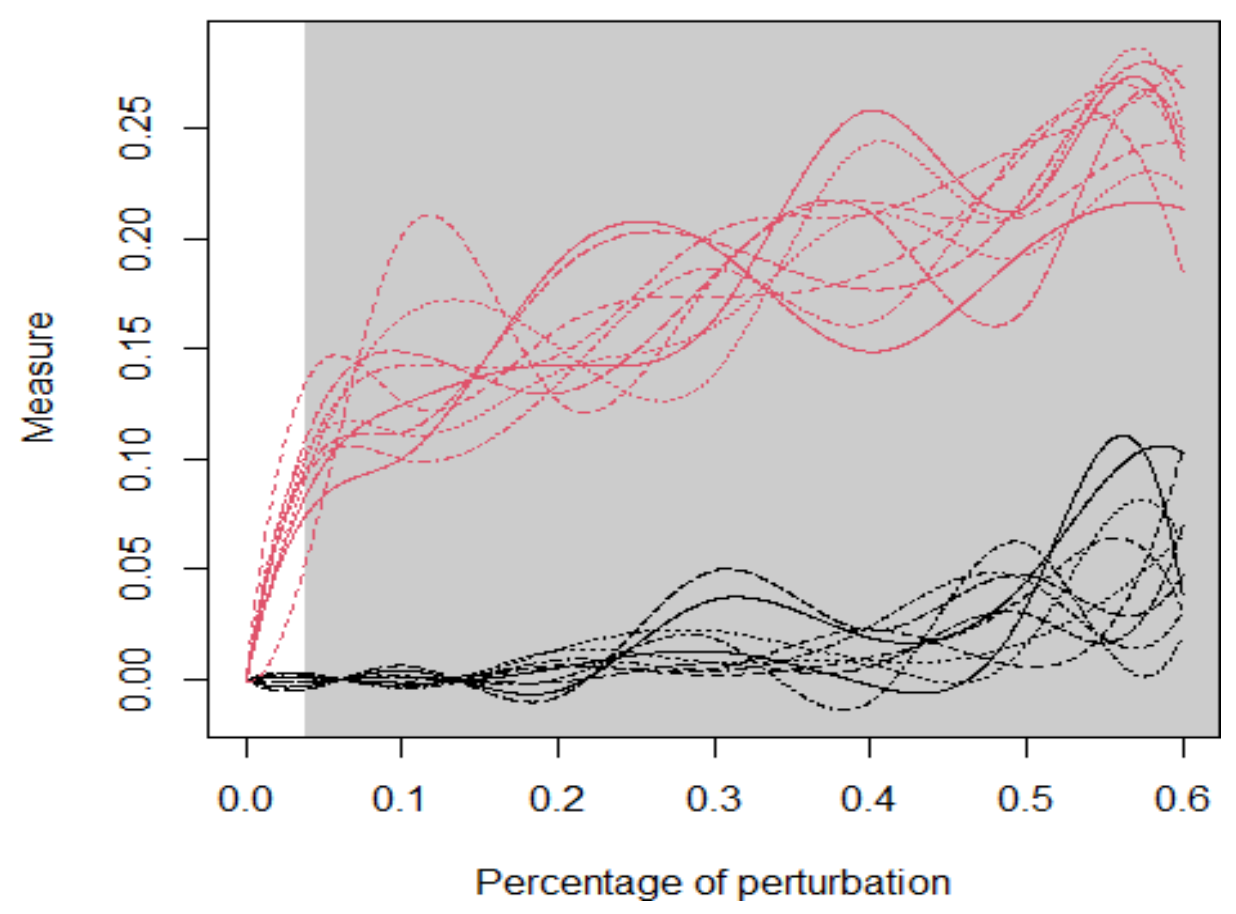

1013

1014

Figure 6: Keyword occurrences: first bibliometric analysis (keywords $n=20$ )

1015

1016

1017

1018 
Measure : Adjusted p-values

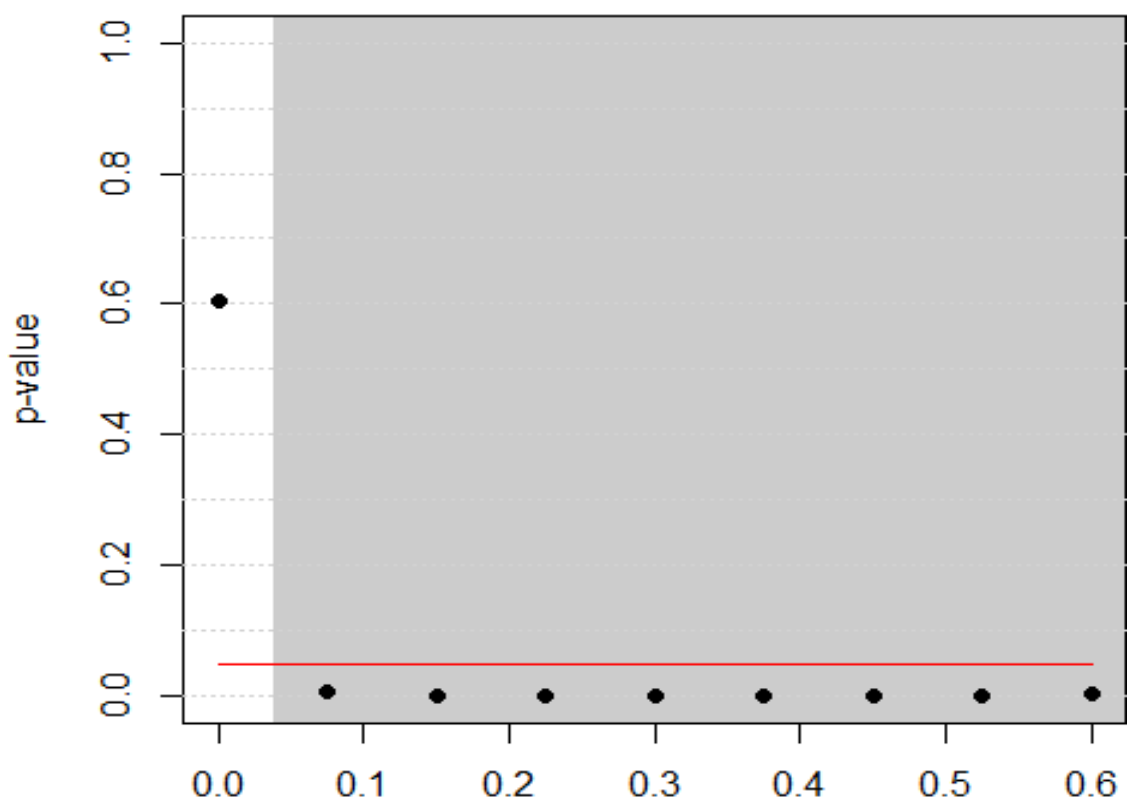

Percentage of perturbation

1020

1021

1022

1023

1024

1025

1026

1027

1028

1029

1030

1031

1032

1033

1034

1035

1036

1037

1038

1039 
1040

1041

1042

1043

Measure : Adjusted p-values

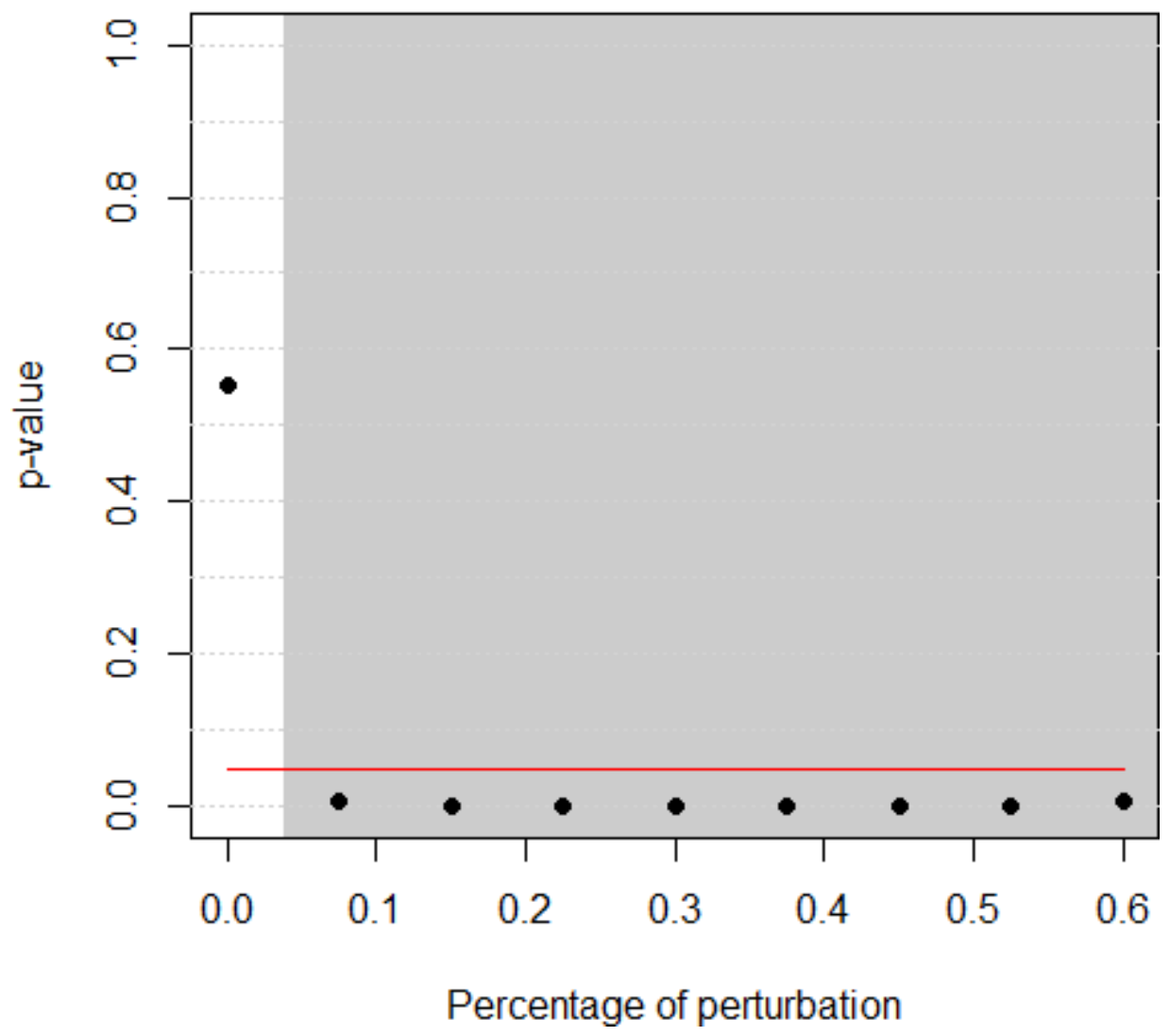


